\title{
ASTRONOMY COURSES FOR ADULTS IN SYDNEY, AUSTRALIA
}

\author{
J.W. O'Byrne \\ The University of Sydney, Australia
}

\section{Introduction}

The University of Sydney has been associated with adult education courses for the general public for at least 70 years and astronomy has often been a part of this activity. Since 1976, these courses have been conducted by a succession of graduate students from the Astronomy and Astrophysics departments within the university. The courses were a part-time activity conducted with limited resources, but served as useful teaching experience. This arrangement continued until the end of 1987 when I left the university. I am pleased to report that this activity is considered sufficiently important to be continued by the permanent academic staff.

Here I seek to briefly report on these astronomy courses by describing those that I conducted at the university over the last five years. I should firstly acknowledge the work of Dr. Graeme White in particular, for his earlier courses and continuing interest. Also, this discussion should be placed in context by recognizing that other astronomy courses are run in Sydney by professional and amateur astronomers through local evening colleges and other organizations. These vary in format, with many of the amateur-run courses emphasizing the practical aspects of sky observing. The displays and facilities provided by the Sydney Observatory also play an important role. Each activity helps to meet the demand in the Sydney region for astronomical education and thereby undoubtedly serves the interests of Australian astronomy.

\section{The Courses}

The courses presented at the University of Sydney were all designed for the general public, assuming nothing other than an intelligent interest. On the other hand, the courses were "academic" in that they attempted to present a broad range of astronomy at a level typical of many college astronomy texts (i.e., largely nonmathematical). The courses were relatively long, with two-hour night-time meetings once a week for up to 19 weeks, and cost up to A $\$ 80$. A starting group of 60 was typical, with more than half attending regularly over a long course. Clearly these people form a highly motivated audience. Many different backgrounds were represented in a class, although the largest single group was usually formed by people in their 20's and 30's, some of them university graduates. Other than a

\footnotetext{
${ }^{1}$ Present Address: The Johns Hopkins University, Applied Physics Laboratory, Laurel, Maryland 20707, U.S.A.
} 
small number of amateur astronomers who wished to reinforce their knowledge of the science of astronomy, few students had any practical experience of observing the night sky.

The first of the two major courses I presented each year was a conventional "survey" of astronomy given largely by a single lecturer. The course started with history and the night sky, proceeded through planetary, stellar and galactic astronomy, and ended with cosmology and SETI. The objective of the course was not to saturate the audience with information, but to impart some understanding that the students could use later in their own reading. There was no specified text and so handouts were used to summarize the lectures and provide diagrams to supplement the notes taken by many people. Slides were valuable tools, notably those provided by David Malin of the Anglo-Australian Observatory. They help to break down the "lecture hall" atmosphere and often prompt wide ranging discussion. Sky \& Telescope "Laboratory Exercises" were of interest to a few, and simple demonstrations like handing out plastic diffraction gratings were always popular.

Questionnaires distributed at the end of the course proved to be a useful way to gauge the interests of the group and assisted in planning future courses. Despite the course being essentially one devoted to theory, its most popular single aspect was the field trips held outside the city. People willingly traveled over $100 \mathrm{~km}$ to view the sky through a variety of telescopes. Perhaps as a result, many people asked for more lecture material on the night sky. Australia's location and climate make the sky a year-round attraction. Also of interest was the description of local astronomical facilities and how astronomy is really done at these observatories. This often came through in discussion, but illustrating the description with the lecturer's own work was regarded as particularly interesting and personal. Other topics, like cosmology, are always popular, and many people requested more of this type of material at the expense of historical background.

Many students finished one course with their appetite whetted for another. However, to do justice to specialized topics requires considerable effort on the part of lecturers not working in the field. Thus shorter courses were organized, with professional astronomers each giving a lecture on a subject of their own interest. Fortunately, there are a large number of potential lecturers available at several astronomical organizations in the Sydney area. The level of presentation was not much deeper than the previous course, but more could be discussed when dealing with a specific topic and a relatively informed audience. Not surprisingly, the dropout rate of students in this course was very low and the lecturers were often surprised by the interest shown and the intelligent questions asked. The topics and lecturers were changed from year to year and many students became regular participants.

There are always a few students who ask for more detailed argument and discussion in a course. This usually means more mathematics and physics, which presented an obstacle to most students who had little or no background in these areas. I presented a single 9-lecture course on stellar evolution in 1987 to try to meet this interest. It proved to be considerably more difficult for all concerned (including the lecturer!), but was well received by the 30 participants. 
There are several major astronomical facilities within several hundred kilometers of Sydney and students often ask if they can visit one at night. Visits at night have been possible at a small university facility, but not at a large observatory. However, several daytime tours to major observatories were arranged and attracted 30 people each for a one-day trip using a chartered DC3 aircraft! The observatories provided a special guided tour and the trips were very successful.

\section{Conclusion}

The conclusion to be drawn from this experience is that there is significant public interest in astronomy in Australia, even at the level of demanding courses. Also, the interaction with enthusiastic practicing astronomers is a particular attraction to students. It is the responsibility of astronomers to be active in adult education, if only because in doing so they will help generate the public support that is vital to the future of astronomy.

\section{Discussion}

H.F. Haupt: In Austria it is possible for all sorts of adults to enroll in university courses, which are free. Many of these people are active or retired teachers, doctors, engineers, etc., who have time and enthusiasm for doing astronomical work even if they do not aim at a degree. These people should be used to help spread astronomical knowledge.

J.R. Percy: At the University of Toronto, those 65 years of age or older can enroll in courses free of charge. They are indeed enthusiastic - in contrast to many of the "regular" students - and represent one of the most receptive audiences for astronomy education. 